prostate instrumentation in the development of prostate infarction remains controversial. ${ }^{10}$

Consequently, we believe that due to all the particularities associated with SARS-CoV-2 infection, the incidence of prostatic infarction resulting in AUR may increase, and urologists should be alert to this phenomenon.

Conflicts of interest and sources of funding: The authors state that there are no conflicts of interest to disclose.

Sergio A. C. Duarte ${ }^{1}$, Jessica G. Pereira ${ }^{1}$, Alexandre Iscaife ${ }^{2}$, Katia R. M. Leite ${ }^{3}$, Alberto A. Antunes ${ }^{2}$

${ }^{1}$ Urology Department, University of Sao Paulo Medical School, Sao Paulo, Brazil; ${ }^{2}$ Division of Urology, Hospital das Clínicas, University of Sao Paulo Medical School, São Paulo, Brazil; ${ }^{3}$ Laboratory of Medical Investigation (LIM55), Urology Department, University of Sao Paulo Medical School, Sao Paulo, Brazil

Contact Sergio Andurte C. Duarte, MD.

E-mail: sergioandurte@gmail.com

1. McFadyen JD, Stevens H, Peter K. The emerging threat of (micro) thrombosis in COVID-19 and its therapeutic implications. Circ Res 2020; 127: 571-87.

2. Chauhan AJ, Wiffen LJ, Brown TP. COVID-19: a collision of complement, coagulation and inflammatory pathways. J Thromb Haemost 2020; Jun 30: https://doi.org/10.1111/jth.14981.

3. Levi M, Thachil J, Iba T, et al. Coagulation abnormalities and thrombosis in patients with COVID-19. Lancet Haematol 2020; 7: e438-40.

4. Chen N, Zhou M, Dong X, et al. Epidemiological and clinical characteristics of 99 cases of 2019 novel coronavirus pneumonia in Wuhan, China: a descriptive study. Lancet 2020; 395: 507-13.

5. Song H, Seddighzadeh B, Cooperberg MR, et al. Expression of ACE2, the SARS-CoV-2 receptor, and TMPRSS2 in prostate epithelial cells. BioRxiv 2020; Apr 25: https://doi.org/10.1101/2020.04.24.056259.

6. Connors JM, Levy JH. COVID-19 and its implications for thrombosis and anticoagulation. Blood 2020; 135: 2033-40.

7. Li D, Jin M, Bao P, et al. Clinical characteristics and results of semen tests among men with coronavirus disease 2019. JAMA Netw Open 2020; 3: e208292.

8. Mjaess G, Karam A, Aoun F, et al. COVID-19 and the male susceptibility: the role of ACE2, TMPRSS2 and the androgen receptor. Prog Urol 2020; 30: 484-7.

9. Henry GH, Malewska A, Joseph DB, et al. A cellular anatomy of the normal adult human prostate and prostatic urethra. Cell Rep 2018; 25 $3530-3542 . e 5$

10. Tuncel A, Uzun B, Eruyar T, et al. Do prostatic infarction, prostatic inflammation and prostate morphology play a role in acute urinary retention? Eur Urol 2005; 48: 277-84.

11. Spiro LH, Labay G, Orkin LA. Role in acute urinary retention. Urology 1974; 3: 345-7.

DOI: https://doi.org/10.1016/j.pathol.2020.09.001

\section{Rapid deployment of pathology services to a remote Australian quarantine setting during the COVID-19 pandemic}

Sir,

In December 2019, a new human coronavirus (SARS-CoV2) with the potential to cause morbidity and mortality
(COVID-19) was detected in China. ${ }^{1}$ The virus has subsequently spread world-wide and a pandemic was declared by the World Health Organization (WHO) in early March $2020 .{ }^{2}$ The rapid emergence of this virus has resulted in unprecedented public health responses from national governments aimed at containment of the outbreak. In early February 2020, like other nations, ${ }^{3}$ the Australian government launched a mission to retrieve Australian citizens from Wuhan, China, caught up in the travel restrictions imposed in the Hubei province. The mission retrieved 278 Australian citizens to Christmas Island, Australia, to undergo quarantine for 14 days. Christmas Island is an Australian external territory situated in the Indian Ocean, $1500 \mathrm{~km}$ west of the Australian mainland. Evacuees were housed in a government facility with essential health care capability for the duration of the quarantine period. The evacuees remained on Christmas Island for a 14 day quarantine period, prior to return by air to the Australian mainland. A timeline of the events associated with planning and deployment of the pathology services to support the operation is summarised in Fig. 1.

The National Critical Care and Trauma Response Centre (NCCTRC) is the Australian Government's Health Emergency Response Capability and coordinates the preparedness and response including logistics, equipment and staff to health emergencies by Australian Medical Assistance Teams (AUSMAT). An AUSMAT, consisting of doctors, nurses, paramedics and logisticians with expertise in public health, primary health care, acute care, infectious diseases and microbiology, was deployed to Christmas Island to provide medical support to the quarantined individuals. A second team travelled to Wuhan to accompany the Australian citizens returning to Australia. NCCTRC is a Commonwealth Department of Health funded organisation sitting within the Northern Territory Department of Health. AUSMAT deployments are funded by the Commonwealth Government through emergency management funding arrangements depending on the type of response. The AUSMAT mobile laboratory capability includes the Biofire FilmArray 1.5 and Biofire FilmArray Torch multiplex Polymerase Chain Reaction systems (BioMérieux, USA) for diagnosing conventional respiratory pathogens. This was supplemented with the deployment by Australian Defence Force (Royal Australian Air Force) of a complete laboratory-based PCR set up, the High-Plex 24 System (AusDiagnostics, Australia), including automated nucleic acid extraction system, a robot with thermocycler for first stage PCR, a real-time PCR thermocycler for second stage amplification/product detection and reagents. Haemotological (Hemocue, Sweden) and biochemical (EPOC Blood Analysis System; Siemens Healthcare, Germany) testing are additional elements of the AUSMAT mobile laboratory capability.

Testing of suspected cases of COVID-19 was based on available Australian case definitions at the time of quarantine. Individuals with clinical evidence of fever or acute respiratory infection (e.g. cough or shortness of breath) regardless of fever were sampled by collection of combined nasopharyngeal and throat swabs. Initial screening for a range of respiratory pathogens was conducted using the Biofire FilmArray Respiratory (RP) Panel (BioMérieux). Negative samples from patients with ongoing symptoms were then subject to testing by a multiplex PCR panel 


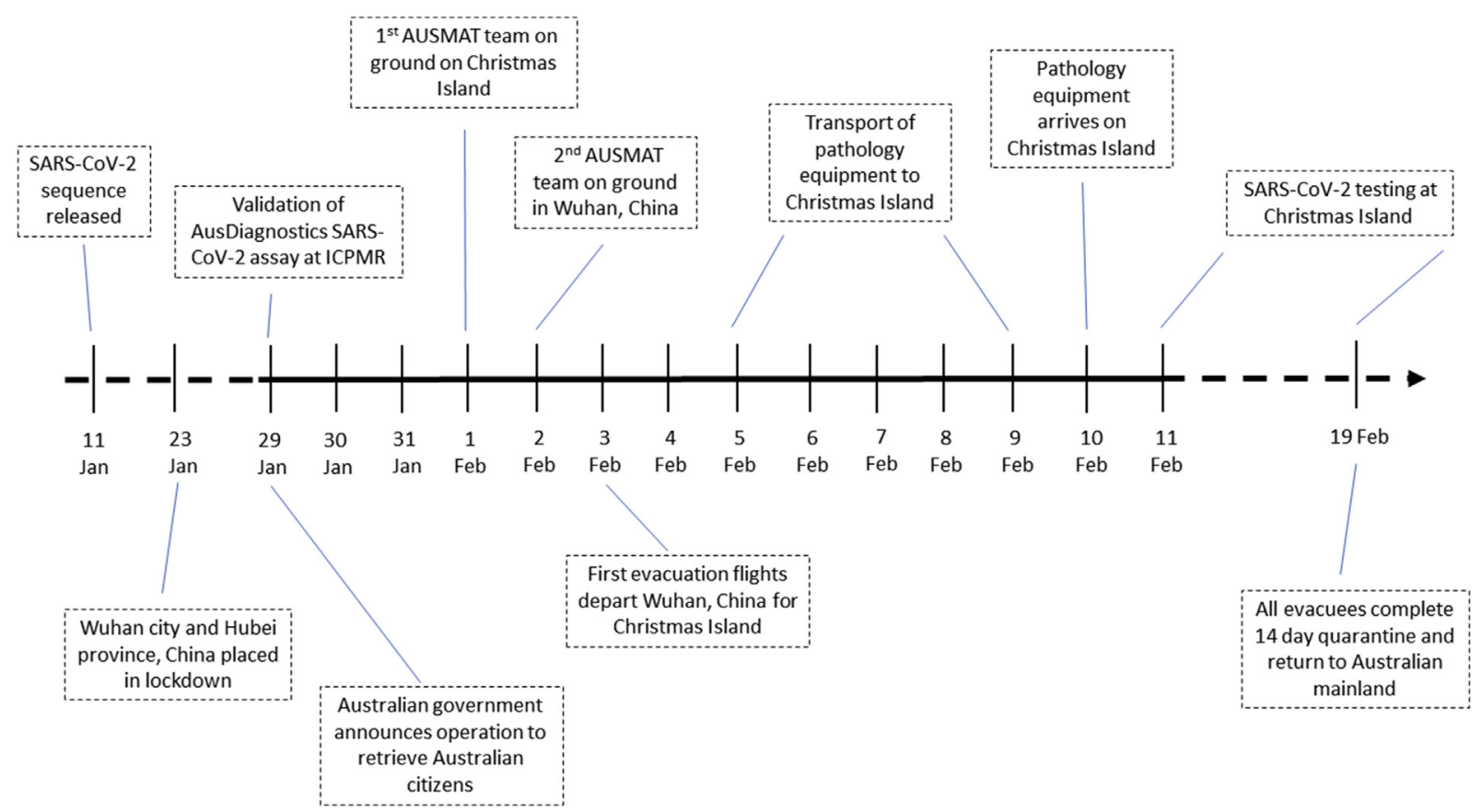

Fig. 1 Timeline of the events associated with the planning and evacuation of Australian citizens to Christmas Island and the deployment of pathology services to commence SARS-CoV2 screening in January - February 2020.

performed on the High-Plex 24 System designed to detect and distinguish the following coronaviruses: HKU1, OC43, 229E, NL63, MERS-CoV, SARS-CoV and SARS-CoV-2 in addition to an internal control. Subsequently, all samples initially collected were screened with this latter assay. RNA was extracted from patient samples using automated extraction system and robotic first round PCR, followed by specific second round PCR with probe detection. Synthetic positive and negative controls were included in each run. Duplicate samples were sent to a reference laboratory via regular military and civilian flights for testing at the Institute of Clinical Pathology and Medical Research (ICPMR), Westmead Hospital, New South Wales, Australia, using a SARS-CoV-2 reverse transcriptase-polymerase chain reaction (RT-PCR) assay targeting the viral E gene. ${ }^{4}$ The reference laboratory results were available within $2-3$ days, including the time required to transport the samples from Christmas Island to ICPMR in Sydney.

Fourteen samples from 12 patients with fever and/or mild respiratory tract symptoms were collected. Initial testing for respiratory pathogens using the FilmArray multiplex led to the diagnosis of rhinovirus/enterovirus infection in one evacuee. Three patients had more persistent or severe symptoms and met the suspect case definition for COVID- 19 . Samples from these patients were tested using the AusDiagnostics assay and were negative for all coronaviruses including SARS-CoV-2. These results were subsequently confirmed by reference laboratory testing.

In this correspondence we highlight the ability to implement advanced testing in a remote environment. The deployment of a commercial nucleic acid detection test for a novel pathogen in a location thousands of kilometres from a reference laboratory illustrates the unprecedented speed and accuracy required of public health response to a new infectious threat. Although no cases of COVID-19 were diagnosed, the AusDiagnostics assay was validated using SARS-CoV-2 positive samples from patients diagnosed at ICPMR Westmead. As a proof of concept, we have shown the successful rapid mobile deployment of conventional laboratory equipment to an extreme location for detection of an emerging respiratory pathogen. Similar actions may be required in other settings as public health agencies attempt to perform mass screening of individuals for SARS-CoV-2 and other emerging pathogens, where access to traditional reference laboratories is logistically challenging.

Acknowledgements: The authors wish to thank members of the Australian Border Force, Australian Government Department of Health, Australian Defence Force and Australian Medical Assistance Team who were involved in this successful operation.

Conflicts of interest and sources of funding: Marin Poljak is a salaried employee of AusDiagnostics. The authors state that there are no conflicts of interest to disclose.

James Branley ${ }^{1,2}$, Matthew O'Sullivan ${ }^{3}$, Adam Polkinghorne ${ }^{1,2}$, Marin Poljak ${ }^{4}$, Dianne Stephens

${ }^{1}$ Department of Microbiology and Infectious Diseases, New South Wales Health Pathology, Nepean Blue Mountains Pathology Service, Penrith, NSW, Australia; ${ }^{2}$ Nepean Clinical School, Faculty of Medicine and Health, University of Sydney, Kingswood, NSW, Australia; ${ }^{3}$ Centre for Infectious Diseases and Microbiology, Institute for Clinical Pathology and Medical Research, Westmead Hospital, Westmead, NSW, Australia; ${ }^{4}$ AusDiagnostics Pty Ltd, Mascot, NSW, Australia; ${ }^{5}$ National Critical Care and Trauma Response Centre, Royal Darwin Hospital, Darwin, NT, Australia 


\section{Contact: Dr James Branley.}

E-mail: james.branley@health.nsw.gov.au

1. Lu R, Zhao X, Li J, et al. Genomic characterisation and epidemiology of 2019 novel coronavirus: implications for virus origins and receptor binding. Lancet 2020; 395: 565-74.

2. Jin Y, Yang H, Ji W, et al. Virology, epidemiology, pathogenesis, and control of COVID-19. Viruses 2020; 12: 372.
3. Hoehl S, Berger A, Kortenbusch M, et al. Evidence of SARS-CoV-2 infection in returning travelers from Wuhan, China. $N$ Engl J Med 2020; 382: 1278-80.

4. Corman VM, Landt O, Kaiser M, et al. Detection of 2019 novel coronavirus (2019-nCoV) by real-time RT-PCR. Euro Surveill 2020; 25: 2000045.

DOI: https://doi.org/10.1016/j.pathol.2020.06.003 